\title{
Obesity and nocturnal gastro-oesophageal reflux are related to onset of asthma and respiratory symptoms
}

\author{
M.I. Gunnbjörnsdóttir*, E. Omenaas\#, T. Gíslason`, E. Norrman ${ }^{+}$, A-C. Olin ${ }^{\S}$, R. Jõgif ${ }^{f}$, E.J. Jensen**, \\ E. Lindberg*, E. Björnsson ${ }^{\uparrow}$, K. Franklin ${ }^{+}$, C. Janson*, on behalf of the RHINE study group \\ The RHINE study group: E.J. Jensen, A. Gulsvik, B. Laerum, E. Omenaas, C. Svanes, A-C. Olin, K. Torén, A. Tunsäter, L. Lillienberg, \\ E. Björnsson, T. Gíslason, D. Gíslason, T. Blöndal, U.S. Björnsdottir, K.B. Jörundsdóttir, R. Jõgi, J. Talvik, B. Forsberg, K. Franklin, \\ B. Lundbäck, E. Norrman, M. Söderberg, M-C. Ledin, G. Boman, C. Janson, E. Lindberg, D. Norbäck, G. Wieslander, U. Spetz-Nyström, \\ K. Stenudd Cashelunge, E. Rydén, M.I. Gunnbjörnsdóttir
}

Obesity and nocturnal gastro-oesophageal reflux are related to onset of asthma and respiratory symptoms. M.I. Gunnbjörnsdóttir, E. Omenaas, T.Gíslason, E. Norrman, A-C. Olin, R. Jõgi, E.J. Jensen, E. Lindberg, E. Björnsson, K. Franklin, C. Janson, on behalf of the RHINE study group. (C) ERS Journals Ltd 2004.

ABSTRACT: Several studies have identified obesity as a risk factor for asthma in both children and adults. An increased prevalence of asthma in subjects with gastrooesophageal reflux (GOR) and obstructive sleep apnoea syndrome has also been reported. The aim of this investigation was to study obesity, nocturnal GOR and snoring as independent risk factors for onset of asthma and respiratory symptoms in a Nordic population.

In a 5-10 yr follow-up study of the European Community Respiratory Health Survey in Iceland, Norway, Denmark, Sweden and Estonia, a postal questionnaire was sent to previous respondents.

A total of 16,191 participants responded to the questionnaire. Reported onset of asthma, wheeze and night-time symptoms as well as nocturnal GOR and habitual snoring increased in prevalence along with the increase in body mass index (BMI). After adjusting for nocturnal GOR, habitual snoring and other confounders, obesity (BMI $>30$ ) remained significantly related to the onset of asthma, wheeze and night-time symptoms. Nocturnal GOR was independently related to the onset of asthma and in addition, both nocturnal GOR and habitual snoring were independently related to onset of wheeze and night-time symptoms.

This study adds evidence to an independent relationship between obesity, nocturnal gastro-oesophageal reflux and habitual snoring and the onset of asthma and respiratory symptoms in adults.

Eur Respir J 2004; 24: 116-121.
*Dept of Medical Sciences: Respiratory Medicine and Allergology, Uppsala University, Uppsala, ${ }^{+}$Dept of Pulmonary Medicine and Allergology, University Hospital of Northern Sweden, Umeå, ${ }^{\S}$ Section of Occupational and Environmental Medicine and Section of Allergology, Sahlgrenska University Hospital, Gothenburg, Sweden, "Dept of Thoracic Medicine and Centre for Clinical Research, Haukeland University Hospital, Bergen, Norway. "Dept of Allergy and Respiratory Medicine, Landspitali University Hospital, Reykjavik, Iceland. ${ }^{f}$ Foundation Tartu University Clinics, Lung Clinic, Tartu, Estonia

Dept of Respiratory Diseases, University Hospital of Aarhus, Aarhus, Denmark.

Correspondence: M.I. Gunnbjörnsdóttir, Dept of Medical Sciences: Respiratory Medicine and Allergology, Akademiska Sjukhuset, SE 75185 Uppsala, Sweden.

Fax: 46186110228

E-mail: maria.gunnbjornsdottir@medsci.uu.se

Keywords: Asthma, epidemiology, gastrooesophageal reflux, habitual snoring, obesity, respiratory symptoms

Received: April 152003

Accepted after revision: January 232004

The study was supported financially by the Icelandic Research Council, the Swedish Heart and Lung Foundation, the Vårdal Foundation for Health Care Science and Allergy Research, the Swedish Association against Asthma and Allergy, the Norwegian Research Council, the Norwegian Asthma and Allergy Association, the Danish Lung Association and the Estonian Science Foundation.
The prevalence of both asthma and obesity is increasing worldwide [1-3]. Several studies have found that obesity is a risk factor for asthma in both children and adults [4-7]. An increased prevalence of asthma in subjects with gastrooesophageal reflux (GOR) [8, 9] and obstructive sleep apnoea syndrome (OSAS) [10] has also been reported. As both GOR and OSAS are related to obesity, it is possible that this may explain the association between obesity and asthma. However, intervention studies do indicate that obesity, GOR and OSAS are independent risk factors of asthma. Weight reduction in obese asthmatics was found to reduce airway obstruction, as well as peak expiratory flow (PEF) variability
[11]. Conversely, medical and surgical anti-reflux treatment reduces asthma symptoms and asthma medication requirement, even though there is little or no effect on lung function $[12,13]$. Furthermore, patients with both OSAS and coexisting asthma showed significant improvement in asthma symptoms and recorded daily PEF rates when treated for sleep apnoea with nasal continuous positive airway pressure [14].

The aim of this study was to evaluate obesity, nocturnal GOR and habitual snoring as independent risk factors for the onset of asthma and respiratory symptoms in Northern European adults. If obesity was associated with increased risk 
of asthma onset, the study would be taken one step further; to assess whether this could be explained by reported nocturnal GOR and/or habitual snoring.

\section{Methods}

\section{The study design and target population}

Respiratory Health in Northern Europe (RHINE) is a follow-up study of participants in the European Community Respiratory Health Survey (ECRHS) stage I, which took place in 1990-1994 [15].

In stage I of the ECRHS, males and females aged 20-44 yrs were randomly selected from the population register in each participating centre. A postal questionnaire was sent to 3,000-4,000 subjects at each centre. Participating centres in Northern Europe were located in the following cities: Reykjavik (Iceland); Bergen (Norway); Aarhus (Denmark); Gothenburg, Uppsala, Umeå (Sweden); and Tartu (Estonia). The average response rate for the ECRHS stage $I$ in the Nordic centres was $83.7 \%$.

The RHINE study was conducted in 1999-2001 in the same seven Nordic centres. A postal questionnaire was sent to eligible subjects $(n=21,802)$. Subjects not responding to the first mailing received two reminders. A total of $16,191(74.3 \%)$ subjects answered the questionnaire.

Responses from the RHINE study were used in the calculations when analysing risk factors. The responses from stage I of the ECRHS were also taken into account when defining the onset of asthma and respiratory symptoms.

\section{Case definition}

An asthma case was defined by answering "yes" to one or both of the questions: "Have you had an attack of asthma in the last 12 months?" and/or "Are you currently taking any medicine (including inhalers, aerosols or tablets) for asthma?". Onset of asthma was defined as answering "no" to both questions in 1990-1994 but "yes" to one or both questions in 1999-2001.

Wheeze was defined as answering "yes" to the question: "Have you had wheezing or whistling in your chest at any time in the last 12 months?" Onset of wheeze was defined as answering "no" to this question in 1990-1994 and answering "yes" to the question in 1999-2001.

Night-time symptoms were defined as answering "yes" to one or both of the questions: "Have you been woken by an attack of shortness of breath at any time in the last 12 months?" and/or "Have you woken up with a feeling of tightness in your chest at any time in the last 12 months?". Onset of night-time symptoms were defined as answering "no" to both questions in 1990-1994 but answering "yes" to either or both questions in 1999-2001.

In the present study, the "onset of respiratory symptoms" is used as a synonym for onset of wheeze and night-time symptoms.

\section{Body mass index}

Body mass index (BMI) was calculated for each subject as weight in kilograms divided by the squared height in meters $\left(\mathrm{kg} \cdot \mathrm{m}^{-2}\right)$. Four groups were defined with BMI $20-<25$ used as reference. Subjects with BMI $<20,25-<30$ and $\geqslant 30$ are referred to, respectively, as being underweight, overweight and obese.

\section{Gastro-oesophageal reflux and snoring}

The questionnaire contained seven multiple-choice questions in which the subjects were asked to estimate the frequency of various sleep-related symptoms on the following 5-point scale: never; less than once a week; 1-2 nights a week; 3-5 nights a week; and almost every night.

The question asked regarding GOR was: "Do you have heartburn or belching when you have gone to bed?". Subjects reporting these symptoms $\geqslant 1-2$ nights per week are, in this study, referred to as reporting nocturnal GOR [16]. The question asked regarding snoring was: "Do you snore loudly and disturbingly?" Subjects reporting snoring $\geqslant 3-5$ times per week are referred to as reporting habitual snoring.

\section{Smoking and rhinitis}

The questions asked were: "Are you a smoker?" and "Are you an ex-smoker?" Subjects were divided into three groups: smokers, exsmokers and never-smokers, based on selfreported smoking status 1999-2001. Participants answering "yes" to the question: "Do you have any nasal allergies including hay fever?" in 1999-2001 are referred to as having rhinitis.

\section{Statistical analysis}

The Chi-squared test and test for trend were used to calculate associations between two nominal variables (univariate analysis). ANOVA with test for equality of variance was used when comparing continuous data with nominal. Multiple logistic regression analyses were performed to analyse the influence of several risk factors, and the results are presented as adjusted odds ratios (OR) with a 95\% CI. In order to detect heterogeneity between centres, the adjusted ORs were calculated separately for each centre. Average effect estimates were derived and potential heterogeneity between centres was examined using standard methods for randomeffects meta-analysis. A p-value of $<0.05$ was regarded as statistically significant.

\section{Results}

A total of 16,191 subjects participated in the study (a response rate of $74.3 \%)$ and $8,587(53.0 \%)$ of the participants were female. The mean \pm SD age of the participants was $39.6 \pm 7.1 \mathrm{yrs}$. The mean follow-up time was $7.9 \mathrm{yrs}$. The mean \pm SD BMI was $24.8 \pm 4.0 \mathrm{~kg} \cdot \mathrm{m}^{-2}$. The characteristics of the study population are given in table 1 .

Compared to the responders in the follow-up, the nonresponders were younger $(30.8 \pm 7.1$ versus $31.9 \pm 7.1 \mathrm{yrs}$, $\mathrm{p}<0.0001)$, reported wheeze more often $(24.1 \%$ versus $21.5 \%$, $\mathrm{p}<0.0001)$, had more night-time symptoms in 1990-1994 $(16.1 \%$ versus $13.9 \%, \mathrm{p}=0.001)$ and were more often male (53.4\% versus $46.6 \%, \mathrm{p}=0.001$ ). No significant difference was found between responders and nonresponders, however, when looking at the prevalence of asthma in 1990-1994 ( $4.3 \%$ versus $4.7 \%, \mathrm{p}=0.20$ ).

The study population, stratified according to BMI groups, is presented in table 2 . Half of the population had a BMI between $20-<25 \mathrm{~kg} \cdot \mathrm{m}^{-2}$. Obesity and being overweight was more common in males, as $51.7 \%$ of males had a BMI $>25 \mathrm{~kg} \cdot \mathrm{m}^{-2}$ compared to $27.1 \%$ of females $(\mathrm{p}<0.0001)$. Subjects in the lowest BMI group were significantly younger $(\mathrm{p}<0.0001)$. The prevalence of nocturnal GOR increased 
Table 1.-Characteristics of the study population

\begin{tabular}{|c|c|c|c|c|c|c|c|c|}
\hline & \multicolumn{8}{|c|}{ Centres } \\
\hline & Reykjavik & Bergen & Aarhus $^{\#}$ & Gothenburg & Uppsala & Umeå & Tartu & All \\
\hline Subjects $\mathrm{n}$ & 1969 & 2506 & 2608 & 2188 & 2572 & 2640 & 1708 & 16191 \\
\hline Participation rate & 67.9 & 72.6 & 71.0 & 76.0 & 81.8 & 80.2 & 69.4 & 74.3 \\
\hline Mean follow-up time yrs & 8.5 & 9.4 & 7.7 & 8.2 & 8.2 & 8.2 & 5.3 & 7.9 \\
\hline Age yrs & $40.9 \pm 7.0$ & $40.5 \pm 6.8$ & $39.1 \pm 7.0$ & $40.4 \pm 7.3$ & $40.4 \pm 7.3$ & $40.6 \pm 7.3$ & $35.6 \pm 7.0$ & $39.6 \pm 7.1$ \\
\hline $\mathrm{BMI} \mathrm{kg} \cdot \mathrm{m}^{-2}$ & $25.3 \pm 4.0$ & $24.7 \pm 4.0$ & $24.3 \pm 4.2$ & $25.0 \pm 3.9$ & $24.6 \pm 3.9$ & $25.2 \pm 4.3$ & $24.2 \pm 4.2$ & $24.8 \pm 4.0$ \\
\hline $\mathrm{BMI} \geqslant 30$ & 11.6 & 7.9 & 8.1 & 9.6 & 6.8 & 8.9 & 9.1 & 8.7 \\
\hline Nocturnal GOR $>1 \cdot$ week $^{-1}$ & 5.2 & 7.7 & 6.7 & 11.2 & 7.4 & 8.2 & 7.4 & 7.7 \\
\hline Snoring $>3 \cdot$ week $^{-1}$ & 20.7 & 16.9 & 17.7 & 20.4 & 18.6 & 20.7 & 12.0 & 18.1 \\
\hline Onset of asthma & 4.4 & 3.8 & 4.0 & 4.3 & 4.2 & 4.9 & 1.3 & 3.9 \\
\hline Onset of wheeze & 9.1 & 13.1 & 11.3 & 12.5 & 11.1 & 12.0 & 14.4 & 11.3 \\
\hline Onset of night-time symptoms & 7.4 & 9.5 & & 8.0 & 8.2 & 8.9 & 13.8 & 9.3 \\
\hline
\end{tabular}

Data are presented as mean \pm SD or per cent, unless otherwise stated. BMI: body mass index; GOR: gastro-oesophageal reflux. ${ }^{\#}$ : incomplete data.

Table 2. - Characteristics of participants in relation to body mass index (BMI)

\begin{tabular}{|c|c|c|c|c|c|c|}
\hline & $\mathrm{BMI}<20$ & $\mathrm{BMI} \geqslant 20-25$ & $\mathrm{BMI} \geqslant 25-<30$ & $\mathrm{BMI} \geqslant 30$ & All & p-value \\
\hline Subjects $n$ & 1222 & 8158 & 5201 & 1393 & 15974 & \\
\hline Females & 83.8 & 57.9 & 38.1 & 51.3 & 52.8 & $<0.0001$ \\
\hline Age yrs & $37 \pm 7.1$ & $39 \pm 7.2$ & $40 \pm 7.2$ & $41 \pm 6.9$ & $39 \pm 7.1$ & $<0.0001$ \\
\hline Nocturnal GOR $>1 \cdot$ week $^{-1}$ & 4.4 & 5.1 & 10.2 & 15.8 & 8.9 & $<0.0001$ \\
\hline Snoring $>3 \cdot$ week $^{-1}$ & 6.7 & 11.9 & 25.7 & 38.6 & 20.7 & $<0.0001$ \\
\hline Onset of asthma & 3.6 & 3.4 & 4.2 & 5.9 & 3.9 & 0.0003 \\
\hline Onset of wheeze & 10.2 & 10.1 & 12.7 & 21.7 & 11.8 & $<0.0001$ \\
\hline Onset of night-time symptoms & 8.2 & 8.5 & 8.9 & 14.1 & 9.1 & $<0.0001$ \\
\hline
\end{tabular}

Data are presented as mean \pm SD or per cent, unless otherwise stated. GOR: gastro-oesophageal reflux.

with higher BMI, and the same pattern could be seen with habitual snoring. Reported onset of asthma, wheeze and night-time symptoms increased in prevalence along with the BMI gradient, with the highest values in subjects with a BMI $>30 \mathrm{~kg} \cdot \mathrm{m}^{-2}$.

As presented in figure 1, the prevalence of asthma onset gradually increased with increasing BMI in both males ( $\mathrm{p}$ for trend $=0.02$ ) and females ( $\mathrm{p}$ for trend=0.03). Similarly, subjects reporting nocturnal GOR (fig. 2) and habitual snoring (fig. 3) exhibited a higher prevalence of asthma and respiratory symptom onset.

The results of the multivariate logistic regression analyses are presented in table 3 . All values were adjusted for age,

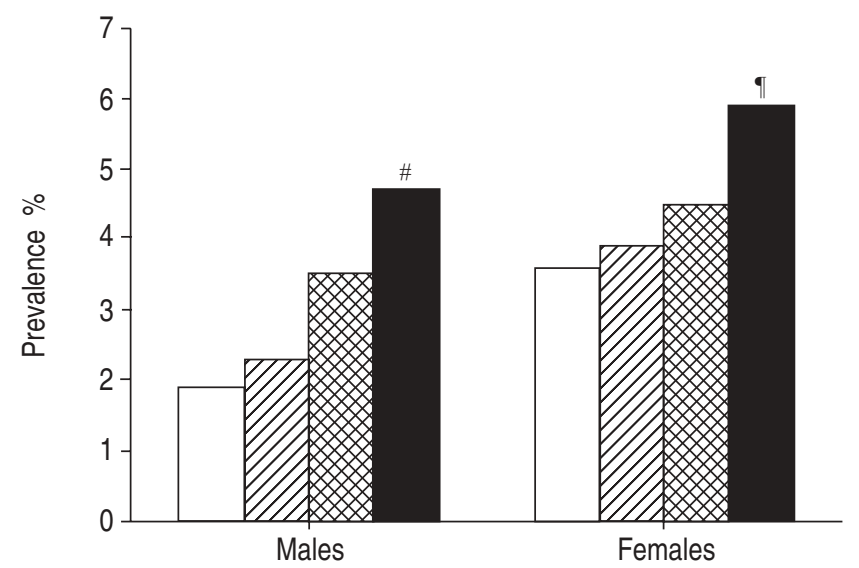

Fig. 1. - The prevalence of asthma onset in relationship to body mass index (BMI) in males and females. $\square$ : BMI $<20$; $\mathbb{Z}$ : BMI $>25-<30$; 口: BMI $>25<30$; $\mathbf{\square}$ : BMI $>30$. ${ }^{\#}: \mathrm{p}<0.02 ;{ }^{\top}: \mathrm{p}<0.03$. centre, smoking, rhinitis and other variables in the table. Obesity and nocturnal GOR were independent risk factors for the onset of asthma, wheeze and night-time symptoms. Habitual snoring was, however, found to be an independent risk factor for the onset of wheeze and night-time symptoms, but not for the onset of asthma. The OR for the onset of asthma and respiratory symptoms in obese subjects (BMI $>30 \mathrm{~kg} \cdot \mathrm{m}^{-2}$ ) changed only slightly after adjustments for nocturnal GOR and/or snoring (table 4). In the same manner, the OR for nocturnal GOR and habitual snoring was only slightly affected when adjusting for obesity.

The sex of the individual did not affect the associations between the onset of asthma, respiratory symptoms, BMI,

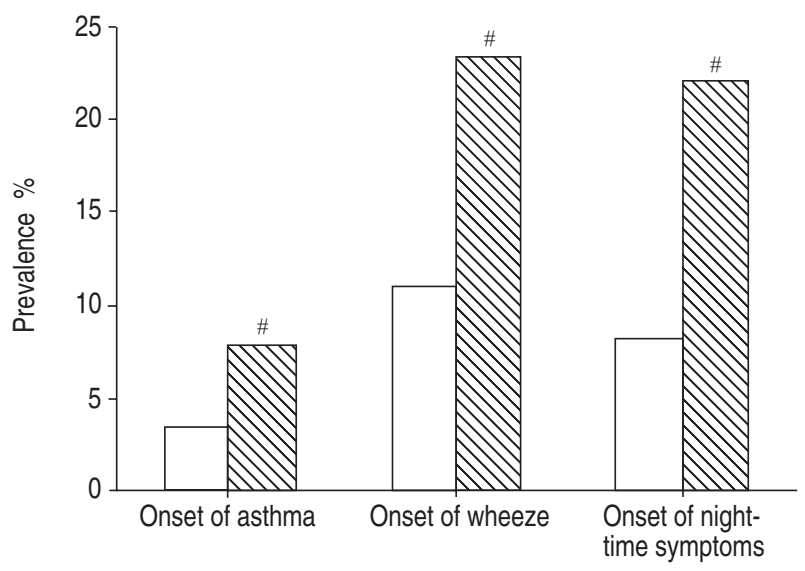

Fig. 2.- The prevalence of asthma and respiratory symptom onset in subjects with $(\mathbb{\mathbb { N }})$ and without $(\square)$ nocturnal gastro-oesophageal reflux. ${ }^{\#}: \mathrm{p}<0.0001$. 


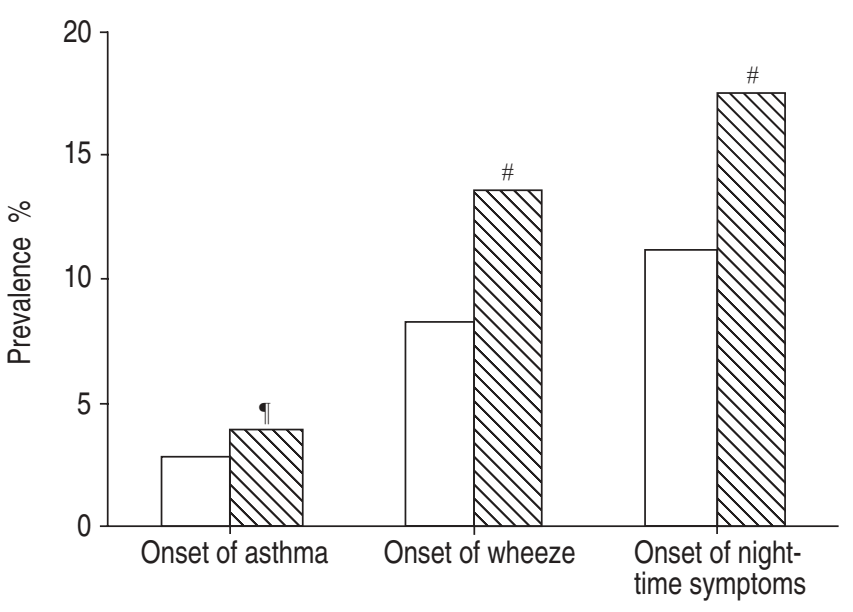

Fig. 3. - The prevalence of asthma and respiratory-symptom onset in subjects with $(\mathbb{\nabla})$ and without $(\square)$ habitual snoring. ${ }^{\#}$ : $\mathrm{p}<0.0001$; ๆ: NS.

nocturnal GOR or habitual snoring. Neither were there any significant interactions between BMI groups, nocturnal GOR and habitual snoring in the association of these variables with onset of asthma or respiratory symptoms.

The association between onset of asthma and respiratory symptoms and obesity, nocturnal GOR and snoring in the different centres was also assessed by meta-analysis. The estimates were very similar to those derived when analysing the pooled data, and no significant centre heterogeneity was detected for any of the risk factors (obesity, nocturnal GOR and habitual snoring) in relation to the onset of asthma or respiratory symptoms.

\section{Discussion}

The central findings in this study were that subjects reporting onset of asthma and respiratory symptoms had higher prevalence of obesity, nocturnal GOR and habitual snoring than subjects not reporting onset of asthma or respiratory symptoms. After adjustments for possible confounders, obesity and nocturnal GOR were found to be independent risk factors for the onset of asthma and respiratory symptoms. Habitual snoring was found to be an independent risk factor for the onset of respiratory symptoms but not for asthma. These risk factors affected males and females in the same way.

Many studies have reported an association between asthma and obesity in children [17-21]. An association between increasing BMI and adult-onset asthma in females was found in the Nurses' Health Study II, and the same study also found that weight gain after 18 yrs was also strongly associated with incident asthma [6]. Two research groups have recently reported associations between weight gain, obesity and asthma diagnosis in females, but not in males [5, 22]. The Italian National Health Survey did, however, find an increased risk for asthma in males with BMI $<20$ and BMI $>30$, but in females the association was more linear [23]. YounG et al. [24] found a linear relationship between BMI and the risk of having asthma in both sexes. The current study found an association between an increasing BMI and onset of asthma in both males and females. This is an important finding which can probably be explained by the large study sample, which offers sufficient incident cases to demonstrate such a relationship in both sexes.

Two publications have reported an association between obesity, asthma and respiratory symptoms. The former found that even though moderate (BMI 30-34.9) and severe obesity $(\mathrm{BMI}>35)$ was a risk factor for asthma and wheeze in the last 12 months; the level of atopy, airway hyperresponsiveness and airway obstruction was not higher in those two groups [25]. The latter found obesity to be a risk factor for selfreported asthma, bronchodilator use and dyspnoea with exertion, but obese participants had the lowest risk for significant airflow obstruction [26]. These data suggest that obstructive airway disease in obese subjects might be overdiagnosed. As the current study is questionnaire-based with no objective measurement, such as spirometry and/or methacholine test, it can be assumed that the same applies for the study population, and may possibly bias the results. The

Table 3. - Odds ratios (OR) for asthma and respiratory symptom onset

\begin{tabular}{lccc}
\hline & Onset of asthma & Onset of wheeze & Onset of night-time symptoms \\
\hline $\begin{array}{l}\text { Females } \\
\text { BMI groups }\end{array}$ & $1.28(1.06-1.55)$ & $1.10(1.00-1.21)$ & $1.19(1.06-1.34)$ \\
$\quad<20$ & $1.01(0.69-1.45)$ & $0.96(0.79-1.15)$ & $1.03(0.82-1.28)$ \\
$\quad \geqslant 20-25$ & 1 & 1 & 1 \\
$\quad \geqslant 25<30$ & $1.14(0.93-1.41)$ & $1.24(1.11-1.40)$ & $1.08(0.95-1.23)$ \\
$\quad 130$ & $1.67(1.24-2.25)$ & $2.23(1.91-2.60)$ & $1.56(1.30-1.88)$ \\
Nocturnal GOR $>1 \cdot$ week $^{-1}$ & $1.82(1.38-2.40)$ & $2.04(1.75-2.38)$ & $3.05(2.60-3.58)$ \\
Snoring $>3 \cdot$ week $^{-1}$ & $1.12(0.89-1.42)$ & $1.53(1.36-1.72)$ & $1.60(1.37-1.82)$ \\
\hline
\end{tabular}

Data are presented as OR $(95 \% \mathrm{CI})$ and are adjusted for age, centre, smoking, rhinitis, sex, body mass index (BMI), nocturnal gastro-oesophageal reflux (GOR) and snoring.

Table 4.-Odds ratios (OR) for asthma and respiratory symptom onset in subjects with body mass index (BMI) $>30$

\begin{tabular}{lllr}
\hline & Onset of asthma & Onset of wheeze & Onset of night-time symptoms \\
\hline Nocturnal GOR $>1 \cdot$ week $^{-1}$ & $1.78(1.33-2.37)$ & $2.47(2.04-2.98)$ & $1.69(1.36-2.10)$ \\
Snoring $>3 \cdot$ week $^{-1}$ & $1.80(1.34-2.42)$ & $2.43(2.01-2.95)$ & $1.67(1.34-2.09)$ \\
Nocturnal GOR and snoring & $1.67(1.24-2.26)$ & $2.27(1.87-2.76)$ & $1.53(1.22-1.91)$ \\
Neither & $1.96(1.46-2.56)$ & $2.66(2.21-3.20)$ & $1.89(1.52-2.33)$ \\
\hline
\end{tabular}

Data are presented as OR $(95 \% \mathrm{CI})$ and are adjusted for age, centre, smoking, rhinitis, sex, BMI, and for nocturnal gastro-oesophageal reflux (GOR) and snoring separately, together or not at all. 
prevalence of atopy in the present study population is also unknown, but adjustment for rhinitis was carried out.

The association between obesity and onset of asthma was relatively unaffected by adjustment for nocturnal GOR and habitual snoring. This in turn indicates that the association is probably not solely explained by the higher prevalence of GOR and obstructive sleep apnoea in obese subjects. Other explanatory mechanisms have been suggested, such as various environmental factors like birth weight, diet and physical activity. Obesity may also affect asthma by enhancing the immune response, by genetic mechanisms or by hormones [27].

Nocturnal GOR was an independent risk factor for onset of asthma and respiratory symptoms in the current study. An association between GOR and asthma has been identified in children and adults, but a cause-effect relationship between the two diseases has not been established [28]. It is also known that the prevalence of GOR is higher among asthma patients than it is among individuals without asthma, and that antireflux treatment can reduce asthma symptoms [29]. One study found gastric ulcer and obesity as independent risk factors for asthma [24]. As no obvious associations are known to exist between asthma and gastric ulcer, the authors of the paper speculated that perhaps some of those responding positively to questions on gastric ulcer also suffered from GOR. Several explanatory mechanisms as to the association between asthma and GOR have been suggested, such as vagally-mediated bronchoconstriction, heightened bronchial reactivity and microaspiration [30].

Habitual snoring is a common condition with a prevalence of $16-48 \%$ among males and $8-27 \%$ among females [31-34], and is one of the main symptom of OSAS. Obesity and GOR are common in subjects with OSAS [35, 36] and bronchial hyperresponsiveness can be found in nonasthmatics with this syndrome [37]. Habitual snoring was independently associated with onset of respiratory symptoms in the current study, even after adjusting for obesity and nocturnal GOR. This suggests a relationship between obstruction in the upper and lower airways, but the mechanisms for these associations remain unclear.

There are several methodological issues that must be addressed regarding this study. It is not possible to determine if obesity increases the risk for onset of asthma or if subjects become obese after their asthma becomes active, because of the cross-sectional nature of the study. The direction of the cause-effect relationship between the two variables or whether there is a true cause-effect relationship cannot be determined. This applies to all other respiratory symptoms and associations found in the study. Another study indicates that asthma itself may increase the risk of experiencing GOR [38]. The cause-effect relationship between reflux and asthma thus remains unclear.

The study is questionnaire based with no objective measurement. This makes it impossible to determine if subjects reporting onset of asthma actually are asthmatics. The questions used in the current study have nevertheless been evaluated in other surroundings and have been found to have high specificity for asthma [39].

It is also possible that an unmeasured variable may have confounded the results. It was nevertheless possible to control for the most important covariants, such as age, centre, smoking and rhinitis. The study is multi-centred and in five different languages, which introduces a possible translation bias. A high internal consistency in the ECRHS questionnaire has however been found, which suggests that international comparisons are not affected by errors due to cross-cultural variations in reporting of symptoms [40]. BMI was calculated from self-reported weight and height, which can possibly induce error. Self-reported height and weight can however be used in epidemiological studies where the subjects are $\leqslant 60$ yrs old [41]. As the subjects participating in this study are $24-53 \mathrm{yrs}$, it is proposed that this method of calculating BMI does not cause any significant error in the study results.

The average respond rate was $74.3 \%$, but only $60 \%$ of the original population responded to both questionnaires, which could, in turn, induce bias. In the first survey, nonresponders were younger males with higher prevalence of wheeze and night-time symptoms than responders. This difference might bias the results, but no significant difference was found in the prevalence of asthma between responders and nonresponders.

The strength of this study lies in the large sample size, which gives sufficient power to control for many potential cofounders simultaneously. The study is population based, which suggests that findings can be applied to other similar populations. The validity of the results is to some extent strengthened by the fact that there were no significant differences in the factors associated with asthma or respiratory symptoms, when the results from each study centre were compared.

In conclusion, an independent relationship between onset of asthma and respiratory symptoms with obesity and nocturnal gastro-oesophageal reflux in both males and females was found. Habitual snoring was an additional risk factor for onset of respiratory symptoms, but not for onset of asthma. This indicates that the previously described association between obesity and asthma is not only related to a higher prevalence of gastro-oesophageal reflux and snoring in obese subjects, and must be explained by other mechanisms.

\section{References}

1. Woolcock AJ, Peat JK. Evidence for the increase in asthma worldwide. Ciba Found Symp 1997; 206: 122-134.

2. Kuczmarski RJ, Flegal KM, Campbell SM, Johnson CL. Increasing prevalence of overweight among US adults. The national health and nutrition examination surveys, 1960 to 1991. JAMA 1994; 272: 205-211.

3. WHO. Obesity: preventing and managing the global epidemic. Report of a WHO Consultation on Obesity. Geneva, WHO, 1997.

4. Beckett W, Belanger K, Gent JF, Holford TR, Leaderer BP Asthma among Puerto Ricane Hispanics: a multi ethnic comparison of risk factors. Am J Respir Crit Care Med 1996; 156: 894-899.

5. Beckett WS, Jacobs DR Jr, Yu X, Iribarren C, Williams OD. Asthma is associated with weight gain in females but not males, independent of physical activity. Am J Respir Crit Care Med 2001; 164: 2045-2050.

6. Camargo CA Jr, Weiss ST, Zhang S, Willett WC, Speizer FE. Prospective study of body mass index, weight change, and risk of adult- onset asthma in women. Arch Intern Med 1999; 159: 2582-2588.

7. Shaheen SO, Sterne JA, Montgomery SM, Azima H. Birth weight, body mass index and asthma in young adults. Thorax 1999; 54: 396-402.

8. Sontag SJ. Gastroesophageal reflux and asthma. Am J Med 1997; 103: 84S-90S.

9. Harding SM, Sontag SJ. Asthma and gastroesophageal reflux. Am J Gastroenterol 2000; 95: Suppl. 8, S23-S32.

10. Gislason T, Janson C, Vermeire P, et al. Respiratory symptoms and nocturnal gastroesophageal reflux: a populationbased study of young adults in three European countries. Chest 2002; 121: 158-163.

11. Hakala K, Stenius-Aarniala B, Sovijarvi A. Effects of weight loss on peak flow variability, airways obstruction, and lung volumes in obese patients with asthma. Chest 2000; 118: 1315-1321.

12. Field SK, Sutherland LR. Does medical antireflux therapy 
improve asthma in asthmatics with gastroesophageal reflux?: a critical review of the literature. Chest 1998; 114: 275-283.

13. Field SK, Gelfand GA, McFadden SD. The effects of antireflux surgery on asthmatics with gastroesophageal reflux. Chest 1999; 116: 766-774.

14. Chan CS, Woolcock AJ, Sullivan CE. Nocturnal asthma: role of snoring and obstructive sleep apnea. Am Rev Respir Dis 1988; 137: 1502-1504.

15. Burney PG, Luczynska C, Chinn S. The European Community Respiratory Health Survey. Eur Respir J 1994; 7: 954 960.

16. Janson C, Gislason T, De Backer W. Daytime sleepiness, snoring and gastroesophageal reflux amongst young adults in three European countries. J Int Med 1995; 237: 277-285.

17. Sommerville SM, Rona RJ, Chinn S. Obesity and respiratory symptoms in primary school. Arch Dis Child 1984; 59: 940944.

18. Schwartz J, Gold D, Dockery D, Weiss ST, Speizer FE. Predictors of asthma and persistent wheeze in a national sample of children in the United States. Am Rev Respir Dis 1990; 142: 894-899.

19. Figueroa-Munoz JI, Chinn S, Rona RJ. Association between obesity and asthma in 4-11 year old children in the UK. Thorax 2001; 56: 133-137.

20. von Mutius E, Schwartz J, Neas LM, Dockery D, Weiss ST. Relation of body mass index to asthma and atopy in children: the National Health and Nutrition Examination Study III. Thorax 2001; 56: 835-838.

21. von Kries R, Hermann M, Grunert VP, von Mutius E. Is obesity a risk factor for childhood asthma? Allergy 2001; 56: 318-322.

22. Chen Y, Dales R, Tang M, Krewski D. Obesity may increase the incidence of asthma in women but not in men: longitudinal observations from the Canadian National Population Health Surveys. Am J Epidemiol 2002; 155: 191-197.

23. Negri E, Pagano R, Decarli A, La Vecchia C. Body weight and the prevalence of chronic diseases. J Epidemiol Community Health 1988; 42: 24-29.

24. Young SY, Gunzenhauser JD, Malone KE, McTiernan A. Body mass index and asthma in the military population of the northwestern United States. Arch Intern Med 2001; 161: 1605-1611.

25. Schachter LM, Salome CM, Peat JK, Woolcock AJ. Obesity is a risk for asthma and wheeze but not airway hyperresponsiveness. Thorax 2001; 56: 4-8.

26. Sin DD, Jones RL, Man SF. Obesity is a risk factor for dyspnea but not for airflow obstruction. Arch Intern Med 2002; 162: 1477-1481.
27. Tantisira K.G., Weiss S.T. Complex interactions in complex traits: obesity and asthma. Thorax 2001; 56: Suppl. II, ii64ii74.

28. Sontag SJ. Why do the published data fail to clarify the relationship between gastroesophageal reflux and asthma? Am J Med 2000; 108: Suppl. 4a, 159S-169S.

29. Richter JE. Gastroesophageal reflux disease and asthma: the two are directly related. Am J Med 2000; 108: Suppl. 4a, 153S-158S.

30. Harding SM. Gastroesophageal reflux and asthma: insight into the association. J Allergy Clin Immunol 1999; 104: 251259.

31. Gislason T, Almqvist M, Eriksson G, Taube A, Boman G. Prevalence of sleep apnea syndrome among Swedish men an epidemiological study. J Clin Epidemiol 1988; 41: 571-576.

32. Lindberg E, Taube A, Janson C, Gislason T, Svardsudd K, Boman GA. 10-year follow-up of snoring in men. Chest 1998; 114: 1048-1055.

33. Enright PL, Newman AB, Wahl PW, Manolio TA, Haponik EF, Boyle PJ. Prevalence and correlates of snoring and observed apneas in 5,201 older adults. Sleep 1996; 19: 531538.

34. Jennum P, Sjol A. Epidemiology of snoring and obstructive sleep apnoea in a Danish population, age 30-60. J Sleep Res 1992; 1: 240-244.

35. Kerr P, Shoenut JP, Millar T, Buckle P, Kryger MH. Nasal CPAP reduces gastroesophageal reflux in obstructive sleep apnea syndrome. Chest 1992; 101: 1539-1544.

36. Samuelson CF. Gastroesophageal reflux and obstructive sleep apnea. Sleep 1989; 5: 475-476.

37. Lin CC, Lin CY. Obstructive sleep apnea syndrome and bronchial hyperreactivity. Lung 1995; 173: 117-126.

38. Zerbib F, Guisset $\mathrm{O}$, Lamouliatte $\mathrm{H}$, Quinton A, Galmiche JP. Effects of bronchial obstruction on lower esophageal sphincter motility and gastroesopageal reflux in patients with asthma. Am J Respir Crit Care Med 2002; 166: 1206-1211.

39. de Marco R, Cerveri I, Bugiani M, Ferrari M, Verlato G. An undetected burden of asthma in Italy: the relationship between clinical and epidemiological diagnosis of asthma. Eur Respir J 1998; 11: 599-605.

40. Sunyer J, Basagana X, Burney P, Anto JM. International assessment of the internal consistency of respiratory symptoms. Am J Respir Crit Care Med 2000; 162: 930-935.

41. Kuczmarski MF, Kuczmarski RJ, Najjar M. Effects of age on validity of self-reported height, weight, and body mass index: findings from the Third National Health and Nutrition Examination Survey, 1988-1994. J Am Diet Assoc 2001; 101: 28-34. 